which Dr. T. B. Sprague has rendered such distinguished service, and even if the theory were set aside, that would not detract from the great obligation under which he has laid the actuarial profession in regard to all the legitimate uses of such tables.

$$
\text { I am, etc., }
$$

GEO. M. LOW.

28 St. ANdrew Square,

Edinburan, 7th August 1907.

\title{
NOTES ON THE BRITISH OFFICES LIFE ANNUITY TABLES (1893).
}

To the Editor of the Transactions of the Faculty of Actuaries,

Sir,-My attention has been called to the fact that the values of the ratio $\mu_{x+\frac{1}{2}} \div m_{x}$, as tabulated in column (9) of Table XI. of niy Paper upon the above subject (p. 323 of the present volume), show irregularities in passing through successive quinquennial values of $x$, which are not in accordance with the theoretical relations of the quantities $m_{x}$ and $\mu_{x+1}$, when deduced on the basis of Makeham's first modification of Gompertz's formula. These irregularities in the Table appear to arise from the fact that $I$ have not computed the values of colog $p_{x}$ (from which $m_{x}$ is deduced) and of $\mu_{x+z}$, as given in columns (6) and (8) respectively, to a sufficient number of places. Mr. D. C. Fraser, M.A., F.I.A., very kindly sends me the following Table, in which the values are more fully computed :-

\begin{tabular}{|c|c|c|c|c|}
\hline$x$ & $\operatorname{colog}{ }_{10} p_{x}$ & $m_{x}$ & $\mu_{x+\frac{1}{2}}$ & $\frac{\mu_{x+1}}{m_{x}}$ \\
\hline 52 & $\cdot 007,894,424$ & $\cdot 018,177,082$ & $018,173,863$ & $\cdot 999,823$ \\
\hline 57 & $\cdot 010,673,839$ & $\cdot 024,576,185$ & $\cdot 024,571,662$ & $\cdot 999,816$ \\
\hline 62 & $\cdot 014,978,643$ & $\cdot 034,486,181$ & $\cdot 034,480,679$ & $\cdot 999,840$ \\
\hline 67 & $021,645,995$ & $\cdot 049,831,430$ & $\cdot 049,827,928$ & $\cdot 999,930$ \\
\hline 72 & $\cdot 031,972,501$ & $\cdot 073,586,172$ & $\cdot 073,598,004$ & $1 \cdot 000,161$ \\
\hline 77 & $\cdot 047,966,365$ & $\cdot 110,334,501$ & $\cdot 110,413,492$ & $1 \cdot 000,716$ \\
\hline 82 & $\cdot 072,737,928$ & $\cdot 167,094,849$ & $\cdot 167,433,931$ & $1 \cdot 002,029$ \\
\hline 87 & $\cdot 111,104,536$ & $\cdot 254,441,440$ & $\cdot 255,748,136$ & $1 \cdot 005,136$ \\
\hline
\end{tabular}

It will be seen that the ratios, given in the last column above, fall to a minimum at age 57, and then steadily increase to the end of life, whilst the values in column (9) of my Table XI. show great irregularities at successive ages. The correction of the values in column (9) necessarily involves consequential alterations in the following columns (10) to (17) of my Table, but the changes in the final values of the constants $A, B, a, \beta$ are very slight, and need not now be followed out, as the Table was only intended to illustrate a particular method of experimental graduation.

I am indebted to Mr. John Spencer, F.I.A., for the following interesting and useful demonstration of the relations of $m_{x}$ and $\mu_{x+\frac{1}{z}}$, when Makeham's law applies :-

Taking the usual approximation for $m_{x}$, we have

$$
\begin{aligned}
m_{x} & =\frac{q_{x}}{1-\frac{1}{2} q_{x}}=2 \begin{array}{l}
1-p_{x} \\
1+p_{x}
\end{array}=2 \frac{1-e^{-\operatorname{colog}_{e} p_{x}}}{1+e^{-\operatorname{colog}_{e} p_{x}}} \\
& =\operatorname{colog}_{e} p_{x}-\frac{\left(\operatorname{colog}_{e} p_{x}\right)^{3}}{12}+\frac{\left(\operatorname{colog}_{e} p_{x}\right)^{5}}{120}- \\
& =\frac{\operatorname{colog} e p_{x}}{1+\frac{\left(\operatorname{colog}_{e} p_{x}\right)^{2}}{12}} \text { approximately. }
\end{aligned}
$$


Again-

$$
\mu_{x+1}=\mathbf{A}+\mathbf{B} c^{x+1}=\mathbf{A}+\mathbf{B}^{\prime} c^{x}+\mathbf{B}^{\prime} c^{x}\left\{\frac{\log _{e} c}{c-1} \cdot c^{\frac{1}{2}}-1\right\}
$$

where $B^{\prime}$ is written for $-\log _{e} g(c-1)$

$$
=\operatorname{colog}_{e} p_{x}+\mathrm{B}^{\prime} c^{x}\left\{\frac{\log _{e} c}{c^{\frac{1}{2}}-c^{-1}}-1\right\}
$$

$$
\text { Now } \quad c^{3}-c^{-\frac{1}{2}}=e^{\log _{e} c}-e^{\log _{e} c}
$$

which, after expansion, $\quad=\log _{e} c+\frac{1}{24}\left(\log _{e} c\right)^{3}+\ldots$

$$
\begin{aligned}
\therefore \frac{\log _{e} c}{c^{t}-c^{-\frac{1}{3}}}-1 & =\frac{\log _{e} c}{\log _{e} c+\frac{1}{24}\left(\log _{e} c\right)^{3}+\ldots}-1 \\
& =-\frac{\left(\log _{e} c\right)^{2}}{24} \text { approximately } ;
\end{aligned}
$$

and $\mu_{x+1}=\operatorname{col} \log _{e} p_{x}-\frac{\left(\log _{e} c\right)^{2}}{24} \mathrm{~B}^{\prime} c^{x}$ very nearly.

It follows from the above that

$$
\begin{aligned}
\frac{\mu_{x+1}}{m_{x}} & =\left[1-\frac{\left(\log _{e} c\right)^{2}}{24} \cdot \frac{\mathrm{B}^{\prime} c^{x}}{\operatorname{colog}_{e} p_{x}}\right]\left[1+\frac{\left(\operatorname{colog}_{e} p_{x}\right)^{2}}{12}\right] \text { approximately, } \\
& =1-\frac{\left(\log _{e} c\right)^{2} \mathbf{B}^{\prime} c^{x}}{24 \operatorname{colog}_{e} p_{x}}+\frac{\left(\operatorname{colog}_{e} p_{x}\right)^{2}}{12}, \text { neglecting the minute final term; } \\
& =1-\frac{\left(\log _{e} c\right)^{2}}{24}+\frac{\mathrm{A}\left(\log _{e} c\right)^{2}}{24 \operatorname{colog}_{e} p_{x}}+\frac{\left(\operatorname{colog}_{e} p_{x}\right)^{2}}{12} \text {. . . . (1), }
\end{aligned}
$$

after inserting for $\mathrm{B}^{\prime} c^{x}$ its equivalent colog $p_{\mathrm{e}}-\mathrm{A}$. The above applies to all tables based on Makeham's hypothesis.

Dealing now with the Male Annuitants Ultimate Table and substituting for $A$ and $\log _{e} c$ their respective values 00651642 and 0874982 , we have

$$
\frac{\mu_{x+1}}{m_{x}}=999681+\frac{.0000020787}{\operatorname{colog}_{\varepsilon} p_{x}}+\frac{\left(\operatorname{colog}_{e} p_{x}\right)^{2}}{12} \text {. . . . (2). }
$$

At the early ages in the Table, where $\operatorname{colog}_{e} p$ only very slightly exceeds $\mathbf{A}$, the ratio is practically equal to unity. As the age advances, the increase in the third term of (2) is for a time less than the decrease in the second term, and the ratio consequently diminishes. Afterwards, however, it increases steadily, until at extreme old ages it appreciably exceeds unity. By differentiation we find that the ratio is a minimum when $\left(\operatorname{colog}_{e} p_{x}\right)^{3}=000012472$, i.e. when $\operatorname{colog}_{e} p_{x}$, and therefore $\mu_{x+1}$, approximately $=\cdot 0232$, at which point $\frac{\mu_{x+1}}{m_{x}}=\cdot 999815$.

Mr. Spencer further remarks that the approximation given by (1) up to age 90 is so close that this expression may safely be used in practice in computing values of $\frac{\mu_{x+1}}{m_{x}}$, the labour attending the accurate determination of $m_{x}$ being thus obviated. Thus, writing (2) in the slightly altered form

$$
\frac{\mu_{x+1}}{m_{x}}=\cdot 999681+\frac{\cdot 0000009028}{\operatorname{colog}_{10} p_{x}}+\cdot 4418\left(\operatorname{colog}_{10} p_{x}\right)^{2}
$$

and using the values of $\operatorname{col}_{10} p_{x}$ given above, it will be found that up to age 77 the numerical values of the ratio, as stown in the final column above, are exactly reproduced, while at ages 82 and 87 the approximation exceeds the true value by merely 2 and 7 respectively in the sixth decimal place.

$$
\text { I am, etc., }
$$

26th August 1907,

THOMAS G. ACKLAND. 